\title{
PEMODELAN TARIKAN PERJALANAN PADA UNIVERSITAS AL MUSLIM BIREUEN
}

\author{
Hamzani ${ }^{1)}$, Mukhlis ${ }^{2)}$ Juli Suadi $^{3)}$ \\ ${ }^{1),}{ }^{2)}$ Dosen Jurusan Teknik Sipil, Universitas Malikussaleh, ${ }^{3)}$ Alumni Teknik Sipil \\ email: ${ }^{I)}$ hamzani.hasbi@gmail.com ${ }^{3)}$ julis_n76@yahoo.co.id
}

\begin{abstract}
Abstrak
Sebagai salah satu area tata guna lahan, pusat kegiatan pendidikan mempunyai intensitas yang cukup tinggi dalam menarik pergerakan, Universitas Almuslim (Unimus) sebagai pusat pendidikan yang berada di kota Matang Glumpangdua Kabupaten Bireuen memberi pengaruh besar terhadap arus pergerakan manusia dan menimbulkan tarikan perjalanan yang berimplikasi pada peningkatan volume lalu lintas. Untuk itu diperlukan kajian mengenai besarnya tarikan perjalanan yang ditimbulkan oleh pusat pendidikan tersebut. Tujuan dari studi ini adalah untuk mengetahui komposisi jenis angkutan dan memodelkan tarikan perjalanan menuju pusat pendidikan. Data primer diperoleh melalui survey tarikan perjalanan, sedangkan data sekunder diperoleh dari administrasi pusat pendidikan berupa data variabel indepeden yaitu luas total lahan, luas lantai aktivitas, luas areal parkir, jumlah mahasiswa, dan jumlah karyawan dan dosen. Hasil analisis penggunaan jenis angkutan menuju Unimus menunjukkan $97,41 \%$ menggunakan jenis angkutan sepeda motor, $1,92 \%$ mobil, dan 0,67 becak. Dari hasil analisis regresi diperoleh persamaan untuk tarikan perjalanan 1 hari yaitu $\mathrm{Y} 1=451,28+0,07$ .$X 4\left(R^{2}=0,960\right)$, untuk satu jam puncak pagi $Y 2=43,96+0,02 . X 4\left(R^{2}=\right.$ 1,000), dan untuk satu jam puncak siang/sore $\mathrm{Y} 3=67,15+0,08 \cdot \mathrm{X} 4\left(\mathrm{R}^{2}=\right.$ $0,887)$ dimana ketiga persamaan tersebut dipengaruhi oleh variabel independen X4 (jumlah mahasiswa).
\end{abstract}

Kata Kunci: tarikan perjalanan, bangkitan perjalanan, pusat pendidikan

\section{Pendahuluan}

Pusat kegiatan pendidikan mempunyai intensitas yang cukup tinggi dalam menarik pergerakan, tata guna lahan pada pusat pendidikan ini menimbulkan interaksi bagi pergerakan arus perjalanan baik dengan tujuan pendidikan maupun untuk tujuan bekerja. Besar tarikan perjalanan tersebut bergantung pada berbagai variabel yang mempengaruhinya sehingga untuk memperkirakan besar tarikan pergerakan tersebut perlu dimodelkan terlebih dahulu variabel-variabel yang akan diteliti. Salah satu tarikan pergerakan yang cukup besar seiring dengan perkembangannya sebagai pusat kegiatan pendidikan adalah tarikan perjalanan menuju Universitas Almuslim.

Unimus sebagai pusat pendidikan yang berada di kota Matang Glumpangdua Kabupaten Bireuen memberi pengaruh besar terhadap arus pergerakan manusia, mengingat jumlah mahasiswa yang dimiliki oleh lembaga ini mencapai 14.360 mahasiswa pada tahun akademik 2011/2012. Dengan demikian jumlah perjalanan disetiap hari perkuliahan menuju kampus terus meningkat dan menimbulkan permasalahan lalu lintas pada jaringan jalan disekitarnya, sehingga pada tahap awal perlu dilakukan studi atau evaluasi untuk mengetahui besarnya tarikan perjalanan menuju pusat pendidikan tersebut. 
Studi mengenai tarikan perjalan menuju pusat pendidikan di kota Matangglumpang Dua untuk mengetahui tingkat keterkaitan antara variabelvariabel independen yang ditinjau terhadap tarikan perjalanan serta model tarikan perjalanan menuju pusat pendidikan tersebut. Apabila besarnya tarikan perjalanan menuju pusat pendidikan di kota ini dapat diketahui, maka diharapkan model tarikan ini dapat dijadikan masukan dalam upaya penataan transportasi kedepan, seperti penataan kebutuhan ruang parkir serta penataan arus lalu lintas menuju pusat pendidikan yang semakin berkembang tersebut. Selain dari itu studi ini adalah untuk mengetahui komposisi jenis angkutan yang menuju pusat pendidikan di Universitas Almuslim dan memodelkan tarikan perjalanannya.

\section{Tinjauan Kepustakaan}

Transportasi adalah kebutuhan turunan (derived demand), artinya seseorang tidak melakukan perjalanan kecuali akibat adanya kebutuhan untuk melakukan aktivitas di tempat yang berbeda dengan tempat berada yang bersangkutan. Upaya berpindah tempat dilakukan mengingat di tempat asal aktivitas yang dimaksudkan tidak dapat dijalankan dengan demikian jelaslah transportasi bukanlah tujuan, tetapi alat untuk mencapai tujuan.

Menurut Tamin (2000), tarikan pergerakan adalah tahapan pemodelan yang memperkirakan jumlah pergerakan yang tertarik ke suatu tata guna lahan atau zona. Pergerakan lalu lintas merupakan fungsi tata guna lahan yang menghasilkan pergerakan lalu lintas. Bangkitan lalu lintas ini mencakup lalulintas yang menginggalkan suatu lokasi, sedangkan lalulintas yang menuju atau tiba ke suatu lokasi. Bangkitan dan tarikan pergerakan terlihat secara diagram pada Gambar 1 (Wells, 1975).

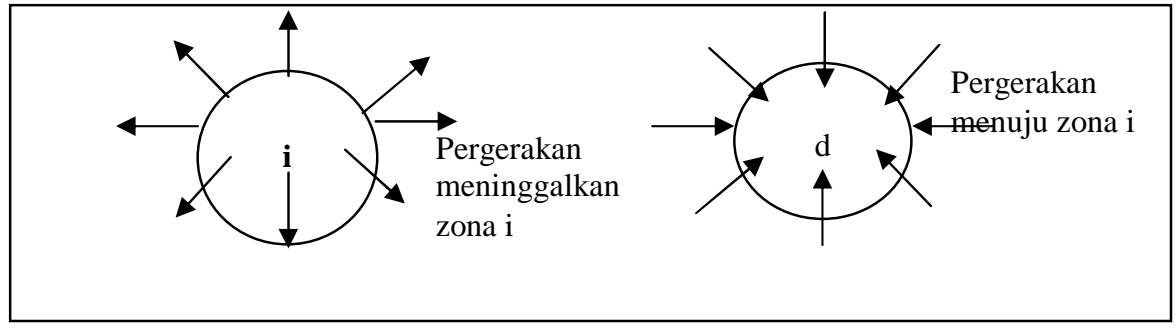

Gambar 1 Bangkitan dan tarikan perjalanan Sumber: Tamin (2000)

Kendaraan yang memasuki area Universitas Almuslim umumnya adalah kendaraan jenis sepeda motor, mobil, dan becak. Semua jenis kendaraan tersebut dikonversikan menjadi satuan mobil penumpang (smp) yaitu dengan mengalikan jumlah kendaraan dengan ekivalensi mobil penumpang (emp). Ekivalensi untuk sepeda motor adalah 0,40, mobil adalah 1,00, dan becak adalah 0,40.

Analisis korelasi bertujuan untuk mengukur kekuatan hubungan linear anatara dua variabel. Korelasi tidak menunjukkan hubungan fungsional atau tidak membedakan antara variabel dependen dengan variabel independen. Korelasi antara variabel tersebut dapat dinyatakan dengan suatu koefisien korelasi (R). Koefesien korelasi mempunyai persamaan sebagai berikut: 


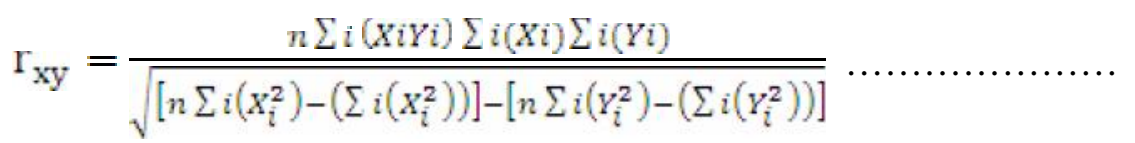

di mana:

$$
\begin{aligned}
& \mathrm{r}_{\mathrm{xy}}=\text { koefesien korelasi atara } \mathrm{x} \text { dan } \mathrm{y} \\
& \mathrm{n}=\text { banyak data }
\end{aligned}
$$

Koefisien determinasi $\left(\mathrm{R}^{2}\right)$ dibaca: $\mathrm{R}$ square digunakan untuk mengukur seberapa jauh kemampuan model dalam menerangkan variasi variabel dependen. Nilai koefesien determinasi adalah antara 0 (nol) dan 1 (satu). Persamaannya:

$$
\mathrm{R}^{2}=\frac{\sum\left(\mathrm{Y}^{*}-\mathrm{Y}^{\sim}\right) / \mathrm{k}}{\sum\left(\mathrm{Y}-\mathrm{Y}^{\sim}\right) / \mathrm{k}}
$$

di mana:

$$
\begin{aligned}
& \mathrm{R}^{2} \quad \text { = Koefesien determinasi } \\
& \mathrm{Y}=\text { Nilai pengamatan } \\
& \mathrm{Y}^{*}=\text { Nilai } \mathrm{Y} \text { yang ditaksir dengan model regresi } \\
& \mathrm{Y}^{\sim}=\text { Nilai rata } \text { - rata pengamatan }
\end{aligned}
$$

Pendekatan yang digunakan adalah analisis regresi linier sederhana, sebagian besar persamaan regresi telah dikembangkan dengan menggunakan paket program analisis regresi SPSS (Statistical Package for Social Science) 16.0 for windows dengan metode (stepwise). Program ini memungkinkan adanya analisis untuk menguji sejumlah besar peubah yang potensial. Pemodel kemudian akan memilih persamaan yang paling baik menggunakan kriteria statistik tertentu. Persamaannya:

$$
Y=a+b . X
$$

di mana:

$$
\begin{array}{ll}
\mathrm{Y} & =\text { peubah dependen } \\
\mathrm{X} & =\text { peubah independen } \\
\mathrm{a} & =\text { konstanta regresi } \\
\mathrm{b} & =\text { koefesien regresi }
\end{array}
$$

\section{Metode Penelitian}

Sebelum melakukan analisis data maka terlebih dahulu dilakukan survey pada lokasi studi yaitu: survey primer dalam penelitian ini merupakan survey tarikan perjalanan (trip attraction survey). Jenis survey primer yang dilakukan untuk mengumpulkan data tarikan dari suatu tata guna lahan tertentu adalah dengan survey pencacahan lalu lintas. Survey pencacahan lalu lintas merupakan suatu pencacahan kendaraan menurut jenisnya. Umumnya di kawasan Universitas Almuslim yang terlihat cukup signifikan adalah kendaraan jenis sepeda motor (SM), mobil (M), dan becak (B). Survey tarikan perjalanan dilaksanakan pada hari kerja selama 11 jam yang dimulai pada pukul 07.00 WIB sampai dengan 18.00 WIB dengan periode waktu pencacahan adalah 15 menit, lokasi pencacahan ditetapkan pada pintu masuk lokasi yang bersangkutan. 
Survey sekunder yang dilakukan untuk mengumpulkan data kawasan dari suatu tata guna lahan tertentu, survey sekunder dilakukan dengan mendatangi lokasi dan melakukan pendataan dengan pihak pengelola Universitas, prosedur pelaksanaan survey ini dilakukan oleh 1 orang surveyor dengan surat pengantar yang ditujukan kepada pimpinan Universitas. Tujuan dilaksanakan survey ini adalah untuk memperoleh data berupa: luas total lahan penelitian $\left(\mathrm{m}^{2}\right)$, luas lantai aktivitas $\left(\mathrm{m}^{2}\right)$, luas areal parkir $\left(\mathrm{m}^{2}\right)$, jumlah mahasiswa (orang), dan jumlah karyawan dan dosen (orang).

Data yang diperoleh kemudian dianalisis meliputi analisis komposisi jenis kendaraan yang dipergunakan dan analisis regresi linear. Adapun variabel dependen $(\mathrm{Y})$ dan variabel independen $(\mathrm{X})$ yang dikaji adalah sebagai berikut:

$\mathrm{Y}_{1} \quad$ : Tarikan perjalanan 1 hari (kendaraan/1 hari).

$\mathrm{Y}_{2}$ : Tarikan perjalanan pada 1 jam puncak siang/sore (kendaraan/1 jam puncak);

$\mathrm{Y}_{3} \quad$ : Tarikan perjalanan pada 1 jam puncak pagi (kendaraan/1 jam puncak);

$\mathrm{X}_{1} \quad$ : Luas total lahan penelitian $\left(\mathrm{m}^{2}\right)$;

$\mathrm{X}_{2} \quad$ : Luas lantai aktivitas $\left(\mathrm{m}^{2}\right)$;

$\mathrm{X}_{3} \quad$ : Luas areal parkir $\left(\mathrm{m}^{2}\right)$;

$\mathrm{X}_{4} \quad$ : Jumlah mahasiswa (orang);

$\mathrm{X}_{5}$ : Jumlah karyawan dan dosen (orang).

Pengolahan data digunakan program SPSS 16.0 for windows dimana SPSS menyediakan berbagai metode perhitungan persamaan regresi dengan banyak variabel dan pada penelitian ini digunakan metode Stepwise. Tahapan penelitiannya sebagai berikut:

\section{Hasil dan Pembahasan}

\subsection{Karakteristik lalulintas}

Dari hasil perhitungan yang dilakukan berdasarkan data survey lalulintas dilakukan selama 4 (empat) hari yaitu: Jumat, Sabtu, Senin, dan Rabu, untuk tarikan perjalanan 1 hari tertinggi terjadi pada hari Senin, untuk tarikan perjalanan pada 1 jam puncak pagi tertinggi juga terjadi pada hari Senin, sedangkan tarikan perjalanan pada 1 jam puncak siang/sore tertinggi terjadi pada hari Rabu. Komposisi jenis angkutan menuju Unimus adalah: sepeda motor sebanyak 1.474 kendaraan (SM) 97,41\%, mobil sebanyak 29 kendaraan (M) 1,92\%, dan becak sebanyak 10 kendaraan (B) $0,67 \%$.

Tabel 1 Karakteristik Tarikan Perjalaan Pada Universitas Almuslim

\begin{tabular}{l|c|c|c|c|c|c}
\hline \multirow{2}{*}{ Lokasi } & \multicolumn{3}{|c|}{ Jenis Angkutan (4 hari) } & \multicolumn{3}{c}{ Jenis Angkutan (1 hari) } \\
\cline { 2 - 7 } & SM & M & B & SM & M & B \\
\hline Kampus Timur & 8.934 & 197 & 73 & 2.233 & 49 & 18 \\
\hline Kampus Induk & 4.764 & 152 & 31 & 1.191 & 38 & 7 \\
\hline Kampus Barat & 3.991 & 0 & 18 & 997 & 0 & 4 \\
\hline Total & & & & 4.422 & 87 & 30 \\
\hline Total Rata-rata & & & & 1.474 & 29 & 10 \\
\hline Persentase & & & & 97,41 & 1,92 & 0,67 \\
\hline
\end{tabular}




\subsection{Model tarikan perjalanan 1 hari}

Model tarikan perjalanan menuju Universitas Almuslim untuk 1 (satu) hari diperoleh dari hasil perhitungan menggunakan softwar SPSS dan analisis data tarikan perjalanan dan data karakteristik kawasan dengan metode analisis regresi linear melalui program SPSS. Maka model tarikan perjalanan 1 hari dapat dituliskan sebagai berikut:

$$
\mathrm{Y} 1=451,28+0,07 \cdot \mathrm{X} 4
$$

di mana:

Y1 = Tarikan perjalanan 1 hari (kendaraan/jam)

X4 = jumlah mahasiswa (orang).

Berdasarkan uji korelasi taraf signifikansi yang digunakan sebesar 5\% memakai uji dua arah diperoleh nilai $F_{1 ; 2 ; 0,05}=18,15$, maka $F_{\text {hitung }}>F_{\text {tabel }}=23,80>$ 18,15 , sehingga mendapat kesimpulan bahwa variasi perubahan variabel independen jumlah mahasiswa (X4) dapat menjelaskan variasi perubahan nilai variabel dependen jumlah tarikan perjalanan 1 hari pada Universitas Almuslim (Y1).

\subsection{Model Tarikan Perjalanan Pada 1 Jam Puncak Pagi dan Siang}

Berdasarkan hasil perhitungan menggunakan softwar SPSS dan analisis tarikan diperoleh hasil yaitu model tarikan perjalanan pada 1 jam puncak pagi dapat dituliskan sebagai berikut:

$$
\mathrm{Y} 2=43,96+0,02 \cdot \mathrm{X} 4
$$

di mana:

Y2 = Tarikan perjalanan pada 1 jam puncak pagi (kendaraan/jam);

X4 = jumlah mahasiswa (orang).

Berdasarkan uji korelasi taraf signifikansi yang digunakan sebesar 5\% memakai uji dua arah diperoleh nilai $F_{1 ; 2 ; 0,05}=18,15$, maka $F_{\text {hitung }}>F_{\text {tabel }}=1.431>$ 18,15 , sehingga mendapat kesimpulan bahwa variasi perubahan variabel independen jumlah mahasiswa (X4) dapat menjelaskan variasi perubahan nilai variabel dependen jumlah tarikan perjalanan pada 1 jam puncak pagi menuju Universitas Almuslim (Y2). Sedangkan model tarikan perjalanan pada 1 jam puncak pagi dapat dituliskan sebagai berikut:

$$
\mathrm{Y} 2=67,15+0,08 \cdot \mathrm{X} 4
$$

di mana:

Y2 = Tarikan perjalanan pada 1 jam puncak sore (kendaraan/jam);

X4 = jumlah mahasiswa (orang).

Taraf signifikansi yang digunakan sebesar 5\% memakai uji dua arah diperoleh nilai $\mathrm{F}_{1 ; 2 ; 0,05}=18,15$, maka $\mathrm{F}_{\text {hitung }}>\mathrm{F}_{\text {tabel }}=73,83>18,15$, sehingga mendapat kesimpulan bahwa variasi perubahan variabel independen jumlah mahasiswa (X4) dapat menjelaskan variasi perubahan nilai variabel dependen 
jumlah tarikan perjalanan pada 1 jam puncak siang/sore menuju Universitas Almuslim (Y3).

\subsection{Karakteristik lalulintas}

Berdasarkan hasil yang didapat bahwa lalulintas kendaraan mahasiswa yang menuju ke kampus Universitas Almuslim (timur, induk, dan barat) lebih dominan menggunakan sepeda motor, dibandingkan jenis lalulintas lainnya, hal ini menjadi pertimbangan bahwa penggunaan jalur jalan masih relatif kecil terhadap kemacetan, namun perlu perhatian serius jika kendaraan mahasiswa menggunakan mobil sebagai kendaraan lalulintas ke kampus, baik dari segi lebar dan jumlah jalur jalan maupun jumlah jaringan jalan.

\subsection{Model tarikan perjalanan 1 hari}

Berdasarkan hasil yang diperoleh untuk 1 (satu) hari adalah Y1 $=451,28+$ 0,07 .X4 dengan nilai korelasi antara variabel independen (X) dan variabel dependen (Y) di atas 0,5 sehingga variabel yang signifikan mempengaruhi tarikan perjalanan 1 hari adalah jumlah mahasiswa (X4) dengan nilai $\mathrm{R}_{\text {square }}$ sebesar 0,976. Model tarikan untuk 1 (satu) hari perjalan dengan nilai $\mathrm{R}$ square sebesar 96,70\% ini menandakan bahwa pengaruh nilai model tarikan 96,70\% disebabkan oleh lalulintas kendaraan mahasiswa, sedangkan sisanya 3,30\% disebabkan oleh faktor-faktor lainnya.

\subsection{Model Tarikan Perjalanan Pada 1 Jam Puncak Siang/Sore}

Berdasarkan hasil yang diperoleh untuk jam puncak pagi adalah Y2 $=43,96$ + 0,02 .X4 dengan nilai Rsquare sebesar 1 (100\%). Dari model tarikan pada jam puncak pagi menunjukkan bahwa pengaruh nilai tarikan perjalanan tersebut $100 \%$ disebabkan oleh lalulintas kendaraan mahasiswa menuju ke kampus Almuslim. Sedangkan berdasarkan hasil yang diperoleh untuk jam puncak sore adalah Y2 = $67,15+0,08 . \mathrm{X} 4$ dengan nilai $\mathrm{R}$ square sebesar $0,887(88,70 \%)$ dengan nilai korelasi antara variabel independen $(\mathrm{X})$ dan variabel dependen $(\mathrm{Y})$ di atas 0,5 sehingga variabel yang signifikan mempengaruhi tarikan perjalanan jam puncak sore $88,70 \%$ dipengaruhi oleh lalulintas kendaraan mahasiswa menuju kampus sedangkan sisanya $11,30 \%$ dipengaruhi oleh faktor-faktor lainnya.

Dari ketiga model tarikan yang dilakukan analisis bahwa model tarikan pada jam puncak pagi yang tinggi pengaruhnya lalulintas kendaraan mahasiswa dengan niali R squar $100 \%$ dibandingkan model tarikan jam puncak sore maupun model tarikan jam puncak 1(satu) hari, hal ini menandakan lalulintas kendaraan masyarakat umum selain lalulintas kendaraan mahasiswa belum relatif tinggi.

\section{Kesimpulan dan Saran}

\subsection{Kesimpulan}

Berdasarkan hasil penelitian maka dapat diambil beberapa kesimpulan antara lain:

1. Dari hasil penelitian di lapangan diperoleh komposisi jenis angkutan yang dipergunakan untuk menuju Universitas Almuslim sebagian besar adalah sepeda motor baik di kawasan Kampus Timur, Kampus Induk, dan Kampus Barat. Adapun persentase komposisinya adalah: sepeda motor 97,41\%, mobil $1,92 \%$, dan becak $0,67 \%$. 
2. Model regresi tarikan perjalanan kendaraan menuju Universitas Almuslim adalah sebagai berikut:

- Model tarikan perjalanan 1 hari (Y1) adalah: Y1 $=451,28+0,07 . X 4$ di mana X4 adalah jumlah mahasiswa, jadi setiap penambahan 1 orang mahasiswa maka tarikan perjalanan bertambah sebesar 0,07 orang/hari, dan $\mathrm{R}_{\text {square }}$ diperoleh sebesar 0,960 .

- Model tarikan perjalanan pada 1 jam puncak pagi (Y2) adalah: $\mathrm{Y} 2=43,96+0,02 . \mathrm{X} 4$ jadi setiap penambahan 1 orang mahasiswa maka tarikan perjalanan yang terjadi akan bertambah sebesar 0,02 orang/jam, dan $\mathrm{R}_{\text {square }}$ diperoleh sebesar 1,000 sehingga $100 \%$ tarikan perjalanan pada 1 jam puncak pagi dipengaruhi oleh jumlah mahasiswa.

- Model tarikan perjalanan pada 1 jam puncak siang/sore (Y3) adalah:

$\mathrm{Y} 3=67,15+0,08 . \mathrm{X} 4$ jadi setiap penambahan 1 orang mahasiswa maka tarikan perjalanan bertambah 0,08 orang/hari, dan $\mathrm{R}_{\text {square }}$ diperoleh 0,887 sehingga $88,7 \%$ tarikan perjalanan pada 1 jam puncak siang dipengaruhi oleh jumlah mahasiswa (X4).

\section{Daftar Kepustakaan}

Departemen Pekerjaan Umum, 1997, Manual Kapasitas Jalan Indonesia (MKJI), Sweroad dan PT. Bina Karya, Jakarta.

Ghozali Imam, 2005, Aplikasi Analisis Multivariated Dengan Program SPSS, Penerbit Universitas Diponogoro, Semarang

Miro Fidel, 2002, Perencanaan Transportasi, Penerbit Erlangga, Jakarta

Tamin, O.Z, 1997, Perencanaan dan Pemodelan Transportasi Penerbit IT, Bandung 